\title{
Microbial Structure and Diversity in Rhizosphere Soil under Different Forest Types in the Subtropical Zone of China
}

\section{Liuting Zhou}

Fujian Agriculture and Forestry University College of Life Science

Jianjuan Li

Fujian Agriculture and Forestry University

Chen Zhang

Fujian Agriculture and Forestry University College of Life Science

\section{Xinlai Guo}

Fujian Agriculture and Forestry University College of Life Science

Wei Chu

Fujian Agriculture and Forestry University College of Life Science

\section{Yanlin Zhao}

Fujian Agriculture and Forestry University College of Life Science

\section{Chengzhen Wu}

Fujian Agriculture and Forestry University

\section{Wenxiong Lin}

Fujian Agriculture and Forestry University College of Life Science

\section{Zeyan Wu ( $\square$ zeyanwu2021@163.com )}

Fujian Agriculture and Forestry University College of Life Science https://orcid.org/0000-0002-70831120

\section{Research Article}

Keywords: Daiyun Mountains, PLFA, Forest types, Elevation, Soil microorganisms

Posted Date: July 13th, 2021

DOI: https://doi.org/10.21203/rs.3.rs-681366/v1

License: (c) (1) This work is licensed under a Creative Commons Attribution 4.0 International License.

Read Full License 
Liuting Zhou ${ }^{\mathrm{a}}$, Jianjuan Li ${ }^{\mathrm{b}}$, Chen Zhang ${ }^{\mathrm{a}}$, Xinlai Guo ${ }^{\mathrm{a}}$, Wei Chu ${ }^{\mathrm{a}}$, Yanlin Zhao ${ }^{\mathrm{a}}$, Wenxiong Lin ${ }^{\mathrm{a}}$, Chengzhen

$4 \quad \mathrm{Wu}^{\mathrm{b}}, \mathrm{Zeyan} \mathrm{Wu}^{\mathrm{a}, \mathrm{c}, \mathrm{d} *}$

$5 \quad{ }^{a}$ College of Life Sciences, Fujian Agriculture and Forestry University, Fujian350002, China.

$6 \quad{ }^{\mathrm{b} C o l l e g e}$ of Forestry, Fujian Agriculture and Forestry University, Fujian350002, China

7 'Fujian Provincial Key Laboratory of Agroecological Processing and Safety Monitoring, School of Life

8 Sciences, Fujian Agriculture and Forestry University, Fuzhou 350002, China.

9 dKey Laboratory of Crop Ecology and Molecular Physiology (Fujian Agriculture and Forestry University),

10 Fujian Province University, Fuzhou 350002, China.

11

12

*Correspondence:

Zeyan Wu

School of Life Sciences,

Fujian Agriculture and Forestry University,

Fuzhou 350002, China

Email: zeyanwu2021@163.com 


\section{Abstract}

The aim of this study was to explore the soil microbial variability within different forest ecosystems (evergreen broad-leaf forest $(\mathrm{EBF})$, coniferous forest $(\mathrm{CF})$, subalpine dwarf forest (SDF) and alpine meadow (AM) at different altitudes in mid-subtropics of China. The phospholipid fatty acid (PLFA) method was used to analyze the microbial communities in rhizosphere soil under different forest types. The relationships were also analyzed between the microbial diversity and soil nutrients. A total of 27 PLFA biomarkers were detected and the PLFA concentrations decreased in the sequence of bacteria $>$ fungus $>$ actinomycete $>$ protozoa in all forest types. The microbial communities in the soil under all forest types were distinct. The


of Simpson, Shannon-Wiener and Brillouin of soil microbial community diversity in these four forest types all showed a trend of $\mathrm{EBF}>\mathrm{CF}>\mathrm{SDF}>\mathrm{AM}$. According to principal component analyses (PCA), the variable variances of principal components 1 and 2 , which were related to the PLFA biomarkers of soil microorganisms, were $67.67 \%$ and $17.91 \%$, respectively. Furthermore, the total PLFAs of different soil microbial groups showed a correlation with soil nutrients and enzyme activities in all forest types. The soil microbial diversity gradually decreased in the order of $\mathrm{EBF}>\mathrm{CF}>\mathrm{SDF}>\mathrm{AM}$ in the Daiyun Mountains. Different vegetation types affect soil microbial community composition and diversity by changing the soil physicochemical properties and enzyme activity.

Key Words: Daiyun Mountains; PLFA; Forest types; Elevation; Soil microorganisms

\section{Introduction}

Microorganisms are one of the most active and influential components of soil ecosystems, and they play an irreplaceable role in soil nutrient transformation and energy cycling (Xue et al. 2008; Zhang et al. 2012; Lerch et al. 2009). Soil microorganisms are sensitive to changes in their 
immediate microenvironment. Therefore, the changes in microorganism community structure can reflect both soil ecosystem changes and environmental stress (White and Rice 2009). However, it is difficult to conduct research on the structures of microbial communities by traditional methods because most microbes cannot be artificially isolated and cultured. In recent years, analysis of phospholipid fatty acid (PLFA) content has been employed to identify and quantitatively describe microbial communities (Xue et al. 2008). Evaluation by PLFA has been widely used to study the soil microbial communities due to its high accuracy, stability and sensitivity (Iovieno et al. 2010; Murphy et al. 2011; Zhang et al. 2013; Lazcano et al. 2013; Marcin et al. 2013).

In forest ecosystems, vegetation type is an important factor that affects soil temperature, humidity, nutrients and microbial activity (Zhang et al. 2013). However, there are few studies that have focused on the relationship between soil microbial community and vegetation type in China. To our knowledge, no studies have examined the various characteristics of soil microbial communities under different forest types in mid-subtropics of China. The Daiyun Mountains, located in southeast of China, have received much attention in recent years because they exhibit a complete distribution of vegetation perpendicular band spectra and contain rich primordial plant resources. It is an ideal place to explore the structure and function of a forest ecosystem under different altitudes. In previous studies, we systematically studied the plant resources and soil characteristics in the Daiyun Mountains. The aim of this study was to explore the microbial variability within different forest ecosystems (evergreen broad-leaf forest, coniferous forest, subalpine dwarf forest and alpine meadow) at different altitudes in the Daiyun Mountains.

\section{Materials and Methods}

\subsection{Soil Sample Collection and Processing}

This study was conducted in the Daiyun Mountain National Nature Reserve, in the Fujian province of China (latitude $25^{\circ} 38^{\prime} 07^{\prime \prime} \sim 25^{\circ} 43^{\prime} 40^{\prime \prime} \mathrm{N}$, longitude $118^{\circ} 05^{\prime} 22^{\prime \prime} \sim 118^{\circ} 20^{\prime} 15^{\prime \prime} \mathrm{E}$ ), with 
an area of approximately $1,3472.4 \mathrm{hm}^{2}$ and an altitude ranging from $650 \mathrm{~m}$ to $1856 \mathrm{~m}$. It is located between the south subtropics and mid-subtropics, and is considered a transition zone with clear transitional characteristics in climate, soil and plants. The average annual temperature ranges from $15.6^{\circ} \mathrm{C}$ to $19.5^{\circ} \mathrm{C}$. The annual precipitation is about $1700 \sim 2000 \mathrm{~mm}$ and the average annual air relative humidity is above $80 \%$. It has 220 foggy days and 260 frost-free days per year. The forest types include evergreen broadleaved forest (EBF), coniferous forest (CF), subalpine dwarf forest (SDF) and alpine meadow (AM), and each vegetation zone is dominated the presence of distinct flora. The EBF zone $(400 \sim 900 \mathrm{~m})$ contains mostly Castanopsis eyrei, Castanopsis fabri, Castanopsis carlesii and Schima superba, the CF zone (900m 1400 m) contains Pinus massoniana and Cunninghamia lanceolata, the SDF zone (1400 1750 m) contains Rhododendron latoucheae, Eurya groffii and Eurya rubiginosa, and the AM zone (1750 1856 m) contains Miscanthus sinensis, Arundinella anomala and Eulaliopsis binata. $20 \mathrm{~m} \times 20 \mathrm{~m}$ sample plots with similar topography, landform, slope direction and gradient in different forest types of EBF (650 m), CF (1000 m), SDF (1500 m) and AM (1850 m). During sampling, 20 samples were collected using a $2 \mathrm{~cm}$ diameter soil sampler and consolidated into one bulk sample corresponding to the soil sample location. Each sample depth was collected from the topsoil to $20 \mathrm{~cm}$ below the topsoil. After each soil sample was consolidated and thoroughly mixed, it was split into two subsamples. One split was passed through a $2 \mathrm{~mm}$ sieve and stored at $4^{\circ} \mathrm{C}$ in a refrigerator to test soil microbial community characteristics and enzymatic activity determination. The second split was naturally dried and sieved and stored for testing soil physico-chemical properties.

\subsection{Soil Physicochemical Properties and Enzymatic Activity Determination}

Soil physicochemical properties were measured using protocols outlined in Methods of forest 
102 soil analysis (State Forestry Administration 2000). The soil $\mathrm{pH}$, total nitrogen (TN), total 103 phosphorus (TP), total potassium (TK) were measured and the soil organic matter (OM) was 104 determined. The soil enzyme activity was tested following the methods described by Guan (1986).

105 Each sample was measured in triplicate and reported as the arithmetic mean.

\subsection{Phospholipid Fatty Acid Separation and Gas Chromatography}

The PLFA biomarker method was used to analyze soil microbial community structure. Briefly,

$1084 \mathrm{~g}$ fresh soil samples were measured into $50 \mathrm{~mL}$ centrifuge tubes with $20 \mathrm{~mL} 0.2 \mathrm{moL} \cdot \mathrm{L}^{-1}$ of a

$109 \mathrm{KOH}$ methanol solution and oscillated for 5 minutes. The centrifuge tubes were then heated for

110 one hour in a $37^{\circ} \mathrm{C}$ water bath and oscillated once every 10 minutes during the heating process.

111 After heating, $3 \mathrm{~mL}$ of a $1.0 \mathrm{~mol} \cdot \mathrm{L}^{-1}$ acetic acid solution was added to each centrifuge tube to

112 neutralize the base and was shaken well. Following neutralization, $10 \mathrm{ml}$ of $\mathrm{n}$-hexane was added

113 to each centrifuge tube, each tube was shaken well to encourage PLFAs to partition into the 114 organic phase, and the tubes were then centrifuged for 15 minutes at $1000 \mathrm{r} \cdot \mathrm{min}^{-1}$. Following 115 centrifugation, $5 \mathrm{ml}$ of the hexane solution was taken into clean glass tubes and

116 solvent-evaporated by nitrogen purging. The substrate was then re-dissolved in $1 \mathrm{~mL}$ of a hexane

117 and methyl butyl ether $(\mathrm{v} / \mathrm{v}=1: 1)$ solution, transferred to a Gas Chromatography vial, and stored 118 at $-20^{\circ} \mathrm{C}$ until analysis by Gas Chromatography Mass Spectrometry (GC-MS). All organic 119 solvents used were High Performance Liquid Chromatography (HPLC) grade reagents. PLFAs 120 were detected using a Varian240 GC-MS. The oven temperature program started at $70^{\circ} \mathrm{C}$ for 1 121 minute (inlet temperature of $280^{\circ} \mathrm{C}$ and a split ratio of $20: 1$ ). The temperature was then increased 122 to $170^{\circ} \mathrm{C}$ at a rate of $20^{\circ} \mathrm{C}$ per minute, held at $170^{\circ} \mathrm{C}$ for 2 minutes, increased to $280^{\circ} \mathrm{C}$ at a rate of $1235^{\circ} \mathrm{C}$ per minute, held at $280^{\circ} \mathrm{C}$ for 5 minutes, increased to $300^{\circ} \mathrm{C}$ at a rate of $40^{\circ} \mathrm{C}$ per minute, and 124 held at $300^{\circ} \mathrm{C}$ for 1.5 minutes (Lin et al. 2013). 
126 The naming convention of PLFA is X:Y $\mathrm{XZ}$ as described in Frostegård et al. (1993) and Ponder

127 et al. (2009), where $X$ represents the total number of carbon atoms in the main chain of the fatty

128 acid. Starting from the carboxyl group, Y, Z and $\omega$ represent the number of unsaturated double

129 bonds, the position of the double bonds (away from the end of methyl) and the existence of

130 double bonds, respectively. In addition to this nomenclature for the PLFA backbone, "c" and " $\mathrm{t}$ "

131 denote $c i s$ - and anti-double bonds, " $\mathrm{i}$ " and "a" denote isomeric and trans-isomeric methyl branch

132 groups, "br" indicates the presence of methyl branch groups of unknown position, "Me"

133 represents the position of methyl side groups, "cy" represents a cyclopropyl group, and the

134 number before $\mathrm{OH}$ represents the position of the hydroxyl group.

135 PLFAs exhibit structural diversity and biological specificity, and thus can be used as 136 biomarkers in different populations in microbial communities. The microbial biomass and the 137 microbial community structure can be identified via quantitative determination of PLFAs. For 138 example, a16:0, i16:0, a17:0, i17:0 and i18:0 is indicative of Gram-positive bacteria; i15:0,

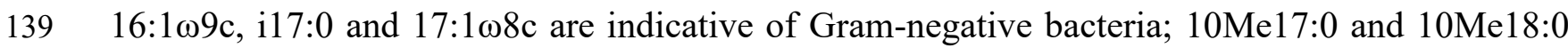

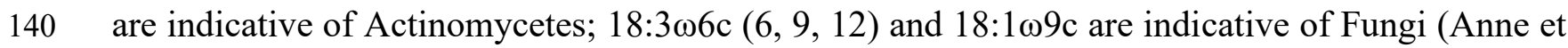
141 al. 2013). The peak area and internal standard curve method were used to test fatty acid 142 quantification with methyl esterification 19:0 and concentrations were reported in $\mathrm{ug} \mathrm{g}^{-1}$ (Zou et 143 al. 2013).

\subsection{Statistical Processing of Data}

145 Microsoft Office 2013 was used for initial data processing and mapping. Single factor analysis 146 of variance, principal component analysis, and diversity index analysis were determined by 147 Statistical Package for the Social Science (SPSS 13.0).

\section{Results and Discussion}


In all soil samples, 27 PLFA biomarkers were detected that showed significantly different distributions among the different forest types (Table 1). There were significant differences in the concentrations of 18 microbial groups found in the soils from the different forest types (e.g., No. 5, 7, 8, 10 and 11, Table 1). Some PLFA biomarkers appeared in all forest, for example,

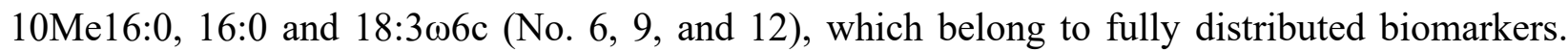
Other biomarkers existed in only some forest type soil samples, which were attributed to incomplete biomarker distribution. For example, 10Me19:0 and i18:0 were only found in EBF soil. As shown in Table 1, most of the microbial species and total PLFA concentrations were higher in low altitude samples than those in high altitude samples. There were 27, 25, 21 and 19 species of PLFA biomarkers in the EBF, CF, SDF and AM forest type soil samples, respectively. The concentration of PLFA biomarkers in the soil samples from these four forest types were $118.60 \pm 1.27 \mathrm{ug} \mathrm{g}^{-1}, 88.90 \pm 1.10 \mathrm{ug} \mathrm{g}^{-1}, 70.32 \pm 0.86 \mathrm{ug} \mathrm{g}^{-1}$ and $49.92 \pm 0.63 \mathrm{ug} \mathrm{g}^{-1}$, respectively. According to the linear relationship between total microbial concentrations and total PLFA biomarkers, we concluded that the concentration of soil microbes gradually decreased in the order of $\mathrm{EBF}>\mathrm{CF}>\mathrm{SDF}>\mathrm{AM}$ in the Daiyun Mountains.

\subsection{Dominant Microflora PLFA Distribution in Different Forest Types}

The highest PLFA biomarkers contents in the soil of different forest types of Daiyun Mountain

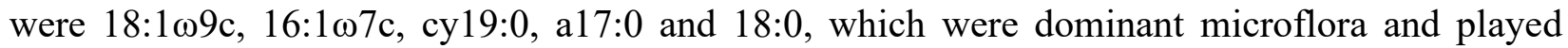
major roles in the soil. The concentration of 5 PLFA biomarkers descended in the sequence of $\mathrm{EBF}>\mathrm{CF}>\mathrm{SDF}>\mathrm{AM}$ in the Daiyun Mountains, indicating that dominant microbial flora presented a similar distribution trend at different elevation. Additionally, the content of biomarker 18:1 $\omega 9 \mathrm{c}$ (an indicator for fungi) was highest in the soil of different forest types, followed by 16:1 $17 \mathrm{c}$ (an indicator for Gram-negative bacteria), and a17:0 accounts for the lowest content (an 
indicator for thermophilic bacillus).

\subsection{Characteristic Microorganisms PLFA Distribution in Different Forest Types}

The characteristic peaks of 16:0, 10Me16:0 and 18:3 $106 \mathrm{c}$ are the main PLFA biomarkers for bacteria, actinomycetes and fungi, respectively (Johansen et al. 2005; Sullivana et al. 2006). As seen in Table 1, the relative biomass of bacteria, fungi and actinomycetes were different in the soil samples from different forest types, of which bacteria was the largest, followed by fungi,

179 followed by actinomycetes. The relative biomass of bacteria and fungi as indicated by PLFA biomarker concentration decreased in the sequence of $\mathrm{EBF}>\mathrm{CF}>\mathrm{SDF}>\mathrm{AM}$, while that of the relative biomass actinomycetes as indicated by PLFA biomarker concentration decreased in the sequence of $\mathrm{EBF}>\mathrm{AM}>\mathrm{SDF}>\mathrm{CF}$. among different forest types, descending in the order of $\mathrm{EBF}>\mathrm{CF}>\mathrm{SDF}>\mathrm{AM}$. The Shannon-Wiener index revealed the species dominance, composition and distribution. The highest Shannon index was found in EBF soil, indicating that the microbial community in this 
soil exhibited the most homogenous distribution. The Brillouin index further weakens the non-random sampling. The significant differences among the calculated Brillouin indexes indicated a high sampling randomness. Simpson index reflects the dominant species of most common species in soil microbial communities. The Simpson indices among the forest type soil samples decreased following the sequence $\mathrm{EBF}>\mathrm{CF}>\mathrm{SDF}>\mathrm{AM}$, but no significant differences were detected. The value of McIntosh index in the AM soil was significantly higher than those in the EBF and CF soil samples.

\subsection{Principal Component Analysis of Soil Microbial Community in Different Forest Types}

The principal components analysis (PCA) of soil PLFA biomarkers in different forest types is illustrated in Figure 1. PCA indicated that the variance was primarily explained by principal component (PC) factors 1 and 2 at $67.67 \%$ and $17.91 \%$, respectively. The EBF soil plotted at the positive terminal of $\mathrm{PC} 1$ and the intersection point of positive and negative terminals of PC2, the CF soil plotted at the positive terminals of PC1 and PC2, the SDF soil plotted at the negative terminals of $\mathrm{PC} 1$ and $\mathrm{PC} 2$, and the $\mathrm{AM}$ soil plotted at the negative terminals of $\mathrm{PC} 1$ and the positive terminal of PC2. PC1 and PC2 were clearly able to distinguish the diversities among the soil microbial communities from different forest types. Based on the correlative analysis between PCA and PLFA biomarkers, 11 PLFA biomarkers appeared to positively correlate with PC1: 16:0,


a16:0, cy17:0, cy19:0 and i17:0 (Table 1). However, only two PLFA biomarkers correlated with PC2: 16:1w9 (positive correlation) and i14:0 (negative correlation).

\subsection{Soil Physicochemical Property and Enzyme Activity in Different Forest Types}

The physicochemical properties of the soil samples from different forest types in the Daiyun Mountains are shown in Table 4. Significant physicochemical differences were detected among all measured parameters except $\mathrm{pH}$. The soil water content ranged from $17.73 \pm 0.24 \%$ to $22.96 \pm$ 
$0.63 \%$, while soil $\mathrm{pH}$ ranged from $4.51 \pm 0.02$ to $4.70 \pm 0.05$, and demonstrated that soil acidity reduced with increasing altitude in the typical southern acid soil. The TN, TP, TK and OM concentrations in the soil samples decreased following the sequence of $\mathrm{EBF}>\mathrm{CF}>\mathrm{SDF}>\mathrm{AM}$. The TN, TP, TK and OM concentrations in AM were $45.23 \%, 56.67 \%, 37.57 \%$ and $30.38 \%$ of those in EBF, demonstrating that soil nutrition gradually decreased with increasing altitude.

Significant differences in soil enzyme activities were observed (Table 5). In four different forest types, enzyme activities of soil phosphomonoesterase, invertase, polyphenol oxidase, urease and catalase decreased in order of $\mathrm{EBF}>\mathrm{CF}>\mathrm{SDF}>\mathrm{AM}$. AM soil enzyme activities were only $67.39 \%, 50.87 \%, 37.80 \%, 41.57 \%$ and $78.06 \%$ of those in EBF. Soil enzyme activities were significantly different among the soils, except for PMEase in EBF or CF and polyphenol oxidase (PPO) in SDF, which exhibited a common characteristic that soil enzyme activities gradually decreased with increasing altitude.

\subsection{Correlation between Microbial PLFA and Soil Nutrients}

The differences in positive correlation coefficient between the total concentrations of PLFA biomarkers for soil bacteria, fungi, actinomycete, protozoa and soil nutrients among the samples are shown in Table 6. The total PLFA biomarkers for bacteria correlated positively with OM, TN and TP. In addition, there was an extremely significant positive correlation between total PLFA biomarkers for bacteria and TK. The total PLFA biomarkers for fungi showed an extremely significant positive correlation with $\mathrm{OM}, \mathrm{TN}$ and $\mathrm{TK}$. The total PLFA biomarkers for actinomycetes showed a significant positive correlation with OM and TK. The total PLFA biomarkers for protozoa showed a significant positive correlation with OM and TN and showed an extremely significant positive correlation with TK. Correlations also existed among total PLFA biomarkers for each microorganism (Table 6). Extremely significant positive correlations were detected between bacteria and fungi as well as total PLFA biomarkers for protozoa. There was a 
significant positive correlation between bacteria and actinomycetes, as well as significant positive correlations among the total PLFA biomarkers for fungi, actinomycetes and protozoa.

\subsection{Correlation between Microbial PLFA and Soil Enzyme Activity}

The correlation coefficient comparisons between soil enzyme activity and the total concentration of PLFA biomarkers for soil bacteria, fungi, actinomycetes, protozoa are shown in Table 7. The total PLFA biomarkers for bacteria showed a significantly positive correlation with PMEase and Ure. In addition, there were extremely significant positive correlations between total PLFA biomarkers for bacteria and PPO or Catalase (CAT). An extremely positive significant correlation was observed between total PLFA biomarkers for fungi and PMEase, and a significant positive correlation was observed between total PLFA biomarkers for fungi and PPO. Extremely significant positive correlations were observed between total PLFA biomarkers for actinomycetes and PMEase and significant positive correlations were observed between total PLFA biomarkers for actinomycetes and PPO. There were also extremely significant positive correlations observed between total PLFA biomarkers for protozoa and PMEase, PPO, Ure or CAT.

\subsection{Correlation between Soil Contents and Microbial Diversity}

260 The correlation coefficient comparisons between the soil contents and microbial diversity among the samples are shown in Table 8. Simpson index showed a significant positive correlation

262 with PPO and Ure. Shannon index showed a significant positive correlation with TN, TP, OM, 263 PMEase and Ure and showed an extremely significant positive correlation with TK, PPO, and 264 CAT. Brillouin index showed a significant positive correlation with TN, TP, Inv and Ure and 265 showed an extremely significant positive correlation with TK, OM, PMEase, PPO, and CAT. 266 McIntosh index showed a significant positive correlation with TK, OM and PMEase and showed 267 an extremely significant positive correlation with $\mathrm{pH}, \mathrm{TN}$, and TP. 
Many factors affect microbial community diversity, and vegetation type was found to be one of the most important factors. Soil microbial diversity arose from the collective effects of soil nutrients, litter and root exudates, etc. Different vegetation types affect soil physical and chemical properties by changing the amount and composition of litter, which leads to different soil microbial composition, quantity and distribution (Han et al. 2007; Wang et al. 2013; Zhang et al. 2013). In the present study, the order of forest soil microbial community diversity was EBF > $\mathrm{CF}>\mathrm{SDF}>\mathrm{AM}$, which showed that vegetation type affected the characteristics of the underground soil microbial community. The forest community varied across elevation gradients in the Daiyun Mountain Nature Reserve which possesses a clear plant succession zone spectrum, resulting in differences in biomass and litter. This study demonstrated that the community diversity in the EBF soil was the highest and the litter concentration was also highest, and decreased in the soil samples from the $\mathrm{CF}, \mathrm{SDF}$, and $\mathrm{AM}$ vegetation zones, respectively. Reduction of vegetation diversity and litter will inevitably affect soil properties of forest stand. The measurements of soil physical-chemical properties and enzyme activities under different forest types showed that the soil nutrient indexes subsequently changed with forest type, which reflected significant differences between soil moisture content, TN, TK, OM, Inv, Ure and CAT, and thus the species and quantities of soil microorganisms. According to the analysis of soil microbial community structure using PLFA technology, the soil physical-chemical properties, enzyme activity and microbial community structure showed a similar trend, which descended in the order of $\mathrm{EBF}>\mathrm{CF}>\mathrm{SDF}>\mathrm{AM}$. Therefore, different vegetation types may lead to different soil microbial community structures and functions under the same site conditions. In general, the species and amount of microbial PLFA biomarkers in EBF were significantly higher than those found in the AM soil. Additionally, the Simpson index, Shannon-Wiener index, and Brillouin index values for soil microbial communities showed the same trend observed for 
physical-chemical properties, enzyme activity and microbial community structure $(\mathrm{EBF}>\mathrm{CF}>$

294 SDF $>$ AM). PCA indicated that PC1 and PC2, which were related to the PLFA biomarkers of soil microorganisms, could explain $67.67 \%$ and $17.91 \%$ of the variance, respectively, and thus could distinguish the majority of the diversity among the microbial communities found in soil from 297 different forest types.

From the analysis of soil microbial community diversity indexes, soil moisture content, Shannon-wiener index and Simpson index of soil microbial communities in EBF and CF were relatively high. High moisture content could accelerate the rate of litter decomposition and enhance the OM concentration, thus benefiting the growth and metabolism of microbes in the soil. The SDF and AM vegetation diversity and coverage were relatively low, and the soil moisture content was low, which would limit the living environmental conditions of soil microbes and thus reduce soil microbial community diversity. Changes in soil moisture led to changes in microbial activity, which agrees with previous research by Gordon et al. (2008) who found that high soil moisture content increased soil microbial activity.

Vegetation secretion and litter are the major sources of carbon and nitrogen to microbes. 309 four studied forest types, and thus affected microbial diversity in these samples. EBF and CF 310 soils were mainly dominated by arbor. They exhibited high species diversity, high root biomass, 311 and high root exudates. These soil characteristics could provide rich carbon and nitrogen sources 312 for soil microbes and thus improved the soil microbial diversity. However, SDF and AM soils 313 were mainly dominated by shrubs and herbage. They exhibited unitary community structure, 314 simple vegetation root systems, low coverage area, little root biomass, and little root exudates. 315 These soil characteristics could result in the reduction of carbon and nitrogen sources required for 316 microbial growth and reproduction and resulted in a decline in the observed soil microbial 317 diversity. 
Soil enzyme activity is an important factor in forest soil ecosystems, and is a key link between the plant and soil nutrient systems, potentially promoting the transformation of material to energy in the ecosystem. Important soil enzymes, such as PMEase, Inv, PPO, Ure and CAT, have been observed to play a significant role in the remobilization of soil nitrogen, phosphorus, potassium and other compounds, thus affecting the microbial diversity indirectly (Alkorta et al. 2003). Moreover, there was a significant relationship between the content of TK, PMEase, PPO, Ure, CAT and soil microbial diversity in different vegetation types based on the correlation analysis between microbial community structure diversity and soil physical-chemical properties. Soil microorganism plays a vital role in the forest sustainable development. The study of soil microorganism community structure and function diversity is important for understanding the relationship between microbes, the environment, and plants. This is especially true with respect to the ways in which soil microbial diversity and vegetation diversity influence each other. The soil microbial diversity had significant impact on vegetation diversity in the Daiyun Mountain forest ecosystems. Under the same site conditions, different vegetation types resulted in variable soil properties, and thus affected the soil microbial composition and diversity, providing a theoretical basis for sustainable management in forest ecosystems. There are many factors that affect the structure and functional diversity of soil microbial community (Iovieno et al. 2010; Murphy et al. 2011). The PLFA biomarker method is a quick method to effectively determine the diversity of soil microbial community structure. In this study, the PLFA biomarker method was employed to analyze the characteristics of soil microbial community structure in different forest types of the Daiyun Mountains and a satisfactory result was achieved. This analysis demonstrated that the concentrations of SOM, TK, PMEase, PPO, Ure, CAT were the main factors affecting the soil microbial diversity.

\section{Conclusion}


This study demonstrated that soil microorganisms and plant types were closely connected to each other in a forest ecosystem. The order of forest soil microbial community diversity was $\mathrm{EBF}>\mathrm{CF}>\mathrm{SDF}>\mathrm{AM}$, which showed that vegetation type affected the characteristics of the underground soil microbial community. The measurements of soil physical-chemical properties and enzyme activities under different forest types showed that the soil nutrient indexes subsequently changed with forest type, which reflected significant differences between soil moisture content, TN, TK, OM, and thus the species and quantities of soil microorganisms. This study reveals the interactions between the composition and structure of the microbial community and soil nutrients in rhizosphere soil, and explores the roles of microorganisms involved in 351 biogeochemical cycling of nutrient elements under different forest types. Our results provide 352 clues to help researchers to more deeply understand the ecological linkages between soil microorganisms and plant types.

Acknowledgments: We would like to thank LetPub (www.letpub.com) for providing linguistic assistance during the preparation of this manuscript. This study was supported by the Chinese National Natural Science Foundation (31500443), Natural Science Foundation of Fujian Province, China (Grant No. 2018J01617), the scientific research foundation of Fujian Agriculture and Forestry University (XJQ201718), and Fujian-Taiwan Joint Innovative Centre for Germplasm Resources and Cultivation of Crop (grant No. 2015-75. FJ 2011 Program, China).

Author contributions: Zeyan $\mathrm{Wu}$, Wenxiong Lin, Yanlin Zhao, Chengzhen $\mathrm{Wu}$ and Liuting Zhou 361 conceived the ideas and designed methodology; Jianjuan Li and Chen Zhang collected the data; Liuting 362 Zhou, Wei Chu and Xinlai Guo analysed the data; Liuting Zhou and Zeyan Wu led the writing of the 363 manuscript. All authors contributed critically to the drafts and gave final approval for publication.

364 Conflict of Interest: The authors declare that they have no conflict of interest. 
Alkorta, I., Aizpurua, A., Riga, P., Albizu, I., Amézaga, I., Garbisu, C.: Soil enzyme activities as biological indicators of soil health. Rev. Environ. Health, 18, 65-73 (2003).

Anne, C.S., McIntosh, S. Ellen Macdonald, Sylvie, A. Quideau: Linkages between the forest floor microbial community and resource heterogeneity within mature lodgepole pine forests. Soil Biol. Biochem., 63, 61-72 (2013).

Lazcano, C., Gómez-Brandón, M., Revilla, P., Domínguez, J.: Short-term effects of organic and inorganic fertilizers on soil microbial community structure and function. Biol. Fert. Soils, 49, 723-733 (2013).

Frostegård, Å., Tunlid, A., Bååth, E.: Phospholipid fatty acid composition, biomass and activity of microbial communities from two soil types experimentally exposed to different heavy metals. Appl. Environ. Microb., 59, 3605-3617 (1993).

Guan, SY.: Soil enzymes and research methods. Agriculture Press, Beijing (1986).

Gordon, H., Haygarth, P. M., Bardgett, R. D.: Drying and rewetting effects on soil microbial community composition and nutrient leaching. Soil Biol. Biochem., 40, 302-311 (2008).

Han, X. M., Wang, R. Q., Liu, J., Wang, M. C., Zhou, J., Guo, W. H: Effects of vegetation type on microbial community structure and catabolic diversity assessed by PolyPhasic methods in North China. J. Environ. Sci-China, 19, 1228-1234 (2007).

Iovieno, P., Alfani, A., Bååth, E.: Soil microbial community structure and biomass as affected by Pinus pinea plantation in two Mediterranean areas. Appl. Soil Ecol., 45, 56-63 (2010).

Joergensen, R. G., Potthoff, M.: Microbial reaction in activity, biomass and community structure after long term continuous mixing of a grassland soil. Soil Biol. Biochem., 37, 1249-1258 (2005).

Johansen, A., Olsson, S: Using phospholipid fatty acid technique to study short term effects of the biological control agent Pseudomonas fluorescens DR54 on the microbial microbiota in barley rhizosphere. Microb. Ecol., 49, 272-281 (2005).

Lerch, T. Z, Dignac, M. F, Nunan, N., Bardoux, G., Barriusoa, E., Mariottib, A.: Dynamics of soil microbial populations involved in 2, 4-D biodegradation revealed by FAME-based stable isotope probing. Soil Biol. Biochem., 41, 77-85 (2009).

Lin, S., Zhuang, J. Q., Chen, T., Zhang, A. J., Zhou, M. M., Lin, W. X.: Microbial diversity in rhizosphere soils of different planting year tea trees; An analysis with phospholipid fatty acid biomarkers. Chin. J. Ecol., 32, 64-71 (2013). 
Marcin, C., Marcin, G., Justyna, M. P., Katarzyna, K., Maria, N.: Diversity of microorganisms from forest soils differently polluted with heavy metals. Appl. Soil Ecol., 64, 7-14 (2013).

Murphy, D. V., Cookson, W. R., Braimbridge, M., Marschner, P., Jones, D. L., Stockdale, E. A., Abbott, L. K.: Relationships between soil organic matter and the soil microbial biomass (size, functional diversity, and community structure) in crop and pasture systems in a semi-arid environment. Soil Res., 49, 582-594 (2011).

Ponder, J. F., Tadros, M., Loewenstein, E. F.: Microbial properties and litter and soil nutrients after two prescribed fires in developing savannas in an upland Missouri Ozark Forest. Forest. Ecol. Manag., 257, 755-763 (2009).

State Forestry Administration: Methods of forest soil analysis. Standards Press of China, Beijing (2000).

Sullivana, T. S., Strombergera, M. E., Paschkeb, M. W.: Parallel shifts in plant and soil microbial communities in response to biosolids in a semi-arid grassland. Soil Biol. Biochem., 38, 449-459 (2006).

Wang, M., Qu, L. Y., Ma, K. M., Yuan, X.: Soil microbial properties under different vegetation types on Mountain Han. Sci. China Life Sci., 56, 561-570 (2013).

White, PA., Rice, C. W.: Tillage effects on microbial and carbon dynamics during plant residue decomposition. Soil Sci. Soc. Am. J., 73, 138-145 (2009).

Xue, D., Yao, H. Y., Ge, D. Y., Huang, C. Y.: Soil microbial community structure in diverse land use systems; A comparative study using Biolog, DGGE, and PLFA analyses. Pedosphere, 18, 653-663 (2008).

Zhang, B., Liang, C., He, H. B., Zhang, X. D.: Variations in Soil Microbial Communities and Residues Along an Altitude Gradient on the Northern Slope of Changbai Mountain, China. Plos One 8, e66184 (2013).

Zhang, X., Zhao, X., Zhang, M.: Functional diversity changes of microbial communities along a soil aquifer for reclaimed water recharge. FEMS Microbiol Ecol., 80, 9-18 (2012).

Zou, J. C., Liu, X. Y., He, C. Q., Zhang, X. Y., Zhong, C. L., Wang, C. H., Wei, J.: Effect of Scripus triqueter of its rhizosphere and root exudates on microbial community structure of simulated diesel-spiked wetland. Int. Biodeter., 82, 110-116 (2013). 

Daiyun Mountains

\begin{tabular}{|c|c|c|c|c|c|c|}
\hline \multirow{2}{*}{ No. } & \multirow{2}{*}{ Biomarkers } & \multirow{2}{*}{ Microbial group } & \multicolumn{4}{|c|}{ Forest types } \\
\hline & & & EBF & $\mathrm{CF}$ & SDF & $\mathrm{AM}$ \\
\hline 1 & 10Me16: 0 & Actinomycetes & $4.12 \pm 0.08 \mathrm{a}$ & $3.23 \pm 0.01 \mathrm{c}$ & $3.32 \pm 0.05 b c$ & $3.40 \pm 0.04 \mathrm{~b}$ \\
\hline 2 & 10Me18: 0 & Actinomycetes & $2.98 \pm 0.04 \mathrm{a}$ & $2.33 \pm 0.04 \mathrm{~b}$ & $1.82 \pm 0.01 \mathrm{c}$ & - \\
\hline 3 & 10Me19: 0 & Actinomycetes & $4.22 \pm 0.05$ & - & - & - \\
\hline 4 & $14: 1 \omega 5 \mathrm{c}$ & Pseudomonas sp. & $2.69 \pm 0.01 \mathrm{a}$ & $1.77 \pm 0.02 \mathrm{c}$ & $2.32 \pm 0.01 \mathrm{~b}$ & $1.70 \pm 0.01 \mathrm{c}$ \\
\hline 5 & 15: 0 & Aerobic bacteria & $2.32 \pm 0.03 b$ & $1.97 \pm 0.03 \mathrm{~d}$ & $2.02 \pm 0.03 c$ & $2.48 \pm 0.03 \mathrm{a}$ \\
\hline 6 & 16: 0 & Gram-negative bacteria & $6.27 \pm 0.12 \mathrm{a}$ & $5.44 \pm 0.05 b$ & $5.15 \pm 0.10 \mathrm{c}$ & $3.87 \pm 0.05 \mathrm{c}$ \\
\hline 7 & $16: 1 \omega 7 \mathrm{c}$ & Gram-negative bacteria & $14.31 \pm 0.18 \mathrm{a}$ & $11.49 \pm 0.20 \mathrm{~b}$ & $8.61 \pm 0.14 \mathrm{c}$ & $5.76 \pm 0.03 \mathrm{~d}$ \\
\hline 8 & 16: $1 \omega 7 \mathrm{t}$ & Aerobic bacteria & $1.43 \pm 0.04 \mathrm{a}$ & $1.24 \pm 0.02 b$ & $1.18 \pm 0.01 \mathrm{c}$ & $1.10 \pm 0.01 \mathrm{~d}$ \\
\hline 9 & $16: 1 \omega 9$ & Gram-negative bacteria & $2.02 \pm 0.02 \mathrm{a}$ & $2.09 \pm 0.03 \mathrm{a}$ & $1.05 \pm 0.01 \mathrm{~b}$ & $2.07 \pm 0.03 \mathrm{a}$ \\
\hline 10 & $16: 1 \omega 5 \mathrm{c}$ & Methane-oxidizing bacteria & $0.94 \pm 0.01 \mathrm{a}$ & $0.81 \pm 0.01 \mathrm{~b}$ & - & - \\
\hline 11 & 18: 0 & Hydrogenobacter & $8.67 \pm 0.13 \mathrm{a}$ & $7.89 \pm 0.13 b$ & $6.38 \pm 0.07 \mathrm{c}$ & $4.97 \pm 0.04 \mathrm{~d}$ \\
\hline 12 & 18: $1 \omega 9 \mathrm{c}$ & Fungi & $18.48 \pm 0.12 \mathrm{a}$ & $12.92 \pm 0.20 \mathrm{~b}$ & $9.82 \pm 0.18 \mathrm{c}$ & $5.68 \pm 0.06 \mathrm{~d}$ \\
\hline 13 & $\begin{array}{l}18: 3 \omega 6 c \\
(6,9,12)\end{array}$ & Fungi & $5.82 \pm 0.02 \mathrm{a}$ & $4.90 \pm 0.03 b$ & $4.07 \pm 0.04 c$ & $2.28 \pm 0.01 \mathrm{~d}$ \\
\hline 14 & $\begin{array}{c}20: 4 \omega 6 \\
(6,9,12,15)\end{array}$ & Protozoa & $1.19 \pm 0.04 \mathrm{c}$ & $0.61 \pm 0.01 b$ & $0.34 \pm 0.01 \mathrm{c}$ & $0.18 \pm 0.01 d$ \\
\hline 15 & $22: 6$ & $\begin{array}{l}\text { Barophilic/psychrophilic } \\
\text { bacteria }\end{array}$ & $1.68 \pm 0.03 b$ & $1.93 \pm 0.02 \mathrm{a}$ & - & - \\
\hline 16 & 23: 0 & Fungi & $0.54 \pm 0.01 \mathrm{~d}$ & $0.95 \pm 0.02 b$ & $1.01 \pm 0.01 \mathrm{a}$ & $0.63 \pm 0.01 \mathrm{c}$ \\
\hline 17 & 9Me18: 0 & Actinomycetes & $0.91 \pm 0.01 \mathrm{a}$ & $0.42 \pm 0.01 \mathrm{~b}$ & $0.34 \pm 0.01 \mathrm{c}$ & \\
\hline 18 & a15: 0 & Gram-positive bacteria & $3.87 \pm 0.07 \mathrm{a}$ & $3.05 \pm 0.04 \mathrm{c}$ & $3.50 \pm 0.02 b$ & $1.96 \pm 0.01 \mathrm{~d}$ \\
\hline 19 & a16: 0 & Gram-positive bacteria & $0.88 \pm 0.01 \mathrm{a}$ & $0.76 \pm 0.01 b$ & - & - \\
\hline 20 & a17: 0 & Gram-positive bacteria & $7.02 \pm 0.10 \mathrm{a}$ & $7.22 \pm 0.06 \mathrm{a}$ & $4.67 \pm 0.04 \mathrm{~b}$ & $3.79 \pm 0.05 \mathrm{c}$ \\
\hline 21 & cy17: 0 & Gram-negative bacteria & $4.89 \pm 0.03 \mathrm{a}$ & $3.52 \pm 0.03 \mathrm{~b}$ & $1.75 \pm 0.01 \mathrm{c}$ & $1.57 \pm 0.02 \mathrm{c}$ \\
\hline 22 & cy19: 0 & Gram-negative bacteria & $9.54 \pm 0.13 \mathrm{a}$ & $7.64 \pm 0.11 b$ & $5.26 \pm 0.06 \mathrm{c}$ & $4.94 \pm 0.03 \mathrm{~d}$ \\
\hline 23 & cy19: $0 \omega 8 \mathrm{c}$ & Burkholderia sp. & $2.40 \pm 0.02 \mathrm{a}$ & $0.82 \pm 0.01 \mathrm{c}$ & $1.43 \pm 0.02 b$ & $0.55 \pm 0.01 \mathrm{~d}$ \\
\hline 24 & i14: 0 & Aerobic bacteria & $3.56 \pm 0.04 b$ & $2.48 \pm 0.03 \mathrm{c}$ & $4.60 \pm 0.08 \mathrm{a}$ & $1.67 \pm 0.22 \mathrm{~d}$ \\
\hline 25 & i16: 0 & Gram-positive bacteria & $1.18 \pm 0.01 \mathrm{c}$ & $1.55 \pm 0.01 \mathrm{a}$ & $1.03 \pm 0.02 \mathrm{~d}$ & $1.32 \pm 0.02 b$ \\
\hline 26 & i17: 0 & Gram-positive bacteria & $2.88 \pm 0.02 \mathrm{a}$ & $1.86 \pm 0.01 b$ & - & - \\
\hline 27 & i1 $18 ; 0$ & Gram-positive bacteria & $3.81 \pm 0.02$ & - & - & - \\
\hline \multicolumn{3}{|c|}{ Total concentration of different PLFA biomarkers } & $118.60 \pm 1.28 \mathrm{a}$ & $88.90 \pm 1.10 b$ & $70.32 \pm 0.86 \mathrm{c}$ & $49.92 \pm 0.64 d$ \\
\hline
\end{tabular}


435 Table 2 PLFA concentrations (ug $\mathrm{g}^{-1}$ ) in $\mathbf{G}^{+}$, $\mathbf{G}^{-}$, Fungi, Actinomycetes and the PLFA proportions found in soils from different forest types in the Daiyun Mountains

\begin{tabular}{ccccc}
\hline \multirow{2}{*}{ Characteristics Microbial communities } & \multicolumn{4}{c}{ Forest type } \\
\cline { 2 - 5 } & EBF & CF & SDF & AM \\
\hline Gram-positive bacteria $\left(\mathrm{G}^{+}\right)$ & $19.64 \pm 0.23$ & $14.45 \pm 0.13$ & $9.21 \pm 0.08$ & $7.06 \pm 0.08$ \\
Gram-negative bacteria $\left(\mathrm{G}^{-}\right)$ & $37.03 \pm 0.48$ & $30.17 \pm 0.42$ & $21.82 \pm 0.32$ & $19.31 \pm 0.16$ \\
$\mathrm{G}^{+} / \mathrm{G}^{-}(\%)$ & 53.04 & 47.88 & 42.19 & 36.57 \\
Fungi & $24.83 \pm 0.15$ & $18.77 \pm$ & $14.89 \pm 0.25$ & $8.58 \pm 0.08$ \\
Fungi/Gram bacteria (\%) & 43.83 & 42.08 & 48.01 & 32.56 \\
Actinomycete & $12.23 \pm 0.18$ & $5.99 \pm 0.06$ & $6.47 \pm 0.07$ & $3.40 \pm 0.04$ \\
\hline
\end{tabular}

Table 3 Diversity indices for soil microbial communities in different forest type of the Daiyun Mountains

\begin{tabular}{ccccc}
\hline Forest type & Simpson index & Shannon index & Brillouin index & McIntosh index \\
\hline EBF & $0.93 \pm 0.02 \mathrm{a}$ & $4.24 \pm 0.04 \mathrm{a}$ & $3.94 \pm 0.05 \mathrm{a}$ & $0.81 \pm 0.02 \mathrm{~b}$ \\
CF & $0.92 \pm 0.04 \mathrm{a}$ & $4.10 \pm 0.04 \mathrm{a}$ & $3.74 \pm 0.02 \mathrm{~b}$ & $0.81 \pm 0.08 \mathrm{~b}$ \\
SDF & $0.92 \pm 0.06 \mathrm{a}$ & $3.96 \pm 0.03 \mathrm{ab}$ & $3.60 \pm 0.04 \mathrm{c}$ & $0.82 \pm 0.02 \mathrm{ab}$ \\
AM & $0.92 \pm 0.03 \mathrm{a}$ & $3.93 \pm 0.08 \mathrm{~b}$ & $3.51 \pm 0.078 \mathrm{c}$ & $0.85 \pm 0.04 \mathrm{a}$ \\
\hline
\end{tabular}

Table 4 Soil chemical properties in different forest type of the Daiyun Mountains

\begin{tabular}{ccccccc}
\hline $\begin{array}{c}\text { Forest } \\
\text { type }\end{array}$ & $\begin{array}{c}\text { Water content } \\
/(\%)\end{array}$ & $\mathrm{pH}$ & $\mathrm{TN} /\left(\mathrm{g} \cdot \mathrm{kg}^{-1}\right)$ & $\mathrm{TP} /\left(\mathrm{g} \cdot \mathrm{kg}^{-1}\right)$ & $\mathrm{TK} /\left(\mathrm{g} \cdot \mathrm{kg}^{-1}\right)$ & $\mathrm{OM} /\left(\mathrm{g} \cdot \mathrm{kg}^{-1}\right)$ \\
\hline $\mathrm{EBF}$ & $22.96 \pm 0.63 \mathrm{a}$ & $4.51 \pm 0.02 \mathrm{a}$ & $3.10 \pm 0.12 \mathrm{a}$ & $0.26 \pm 0.05 \mathrm{a}$ & $15.33 \pm 0.47 \mathrm{a}$ & $47.79 \pm 0.62 \mathrm{a}$ \\
$\mathrm{CF}$ & $21.42 \pm 0.75 \mathrm{~b}$ & $4.50 \pm 0.01 \mathrm{ab}$ & $2.85 \pm 0.03 \mathrm{~b}$ & $0.25 \pm 0.03 \mathrm{a}$ & $11.39 \pm 0.09 \mathrm{~b}$ & $35.07 \pm 0.84 \mathrm{~b}$ \\
$\mathrm{SDF}$ & $18.93 \pm 0.49 \mathrm{c}$ & $4.58 \pm 0.02 \mathrm{ab}$ & $2.09 \pm 0.04 \mathrm{c}$ & $0.20 \pm 0.01 \mathrm{~b}$ & $9.06 \pm 0.23 \mathrm{c}$ & $30.24 \pm 0.51 \mathrm{c}$ \\
$\mathrm{AM}$ & $17.73 \pm 0.24 \mathrm{~d}$ & $4.70 \pm 0.05 \mathrm{~b}$ & $1.40 \pm 0.02 \mathrm{~d}$ & $0.14 \pm 0.01 \mathrm{c}$ & $5.76 \pm 0.16 \mathrm{~d}$ & $14.52 \pm 0.15 \mathrm{~d}$ \\
\hline
\end{tabular}

Table 5 Soil enzyme activities at different forest type of the Daiyun Mountains

\begin{tabular}{cccccc}
\hline Types & $\begin{array}{c}\text { PMEase } \\
\left(\mathrm{mg} \cdot \mathrm{g}^{-1} \cdot \mathrm{h}^{-1}\right)\end{array}$ & Inv $\left(\mathrm{mg} \cdot \mathrm{g}^{-1} \cdot \mathrm{d}^{-1}\right)$ & $\begin{array}{c}\text { PPO } \\
\left(\mathrm{mg} \cdot \mathrm{g}^{-1} \cdot 2 \mathrm{~h}^{-1}\right)\end{array}$ & Ure $\left(\mathrm{mg} \cdot \mathrm{g}^{-1} \cdot \mathrm{d}^{-1}\right)$ & $\begin{array}{c}\text { CAT } \\
\left(\mathrm{ml} \cdot \mathrm{g}^{-1} \cdot 20 \mathrm{~min}^{-1}\right)\end{array}$ \\
\hline EBF & $1.48 \pm 0.09 \mathrm{a}$ & $17.42 \pm 0.15 \mathrm{a}$ & $0.08 \pm 0.005 \mathrm{a}$ & $0.70 \pm 0.08 \mathrm{a}$ & $1.67 \pm 0.06 \mathrm{a}$ \\
CF & $1.24 \pm 0.05 \mathrm{~b}$ & $15.13 \pm 0.12 \mathrm{~b}$ & $0.05 \pm 0.002 \mathrm{~b}$ & $0.38 \pm 0.05 \mathrm{~b}$ & $1.48 \pm 0.09 \mathrm{~b}$ \\
SDF & $1.18 \pm 0.02 \mathrm{~b}$ & $14.15 \pm 0.06 \mathrm{c}$ & $0.03 \pm 0.003 \mathrm{c}$ & $0.33 \pm 0.03 \mathrm{c}$ & $1.35 \pm 0.05 \mathrm{c}$ \\
AM & $0.99 \pm 0.03 \mathrm{c}$ & $8.86 \pm 0.03 \mathrm{~d}$ & $0.03 \pm 0.001 \mathrm{c}$ & $0.29 \pm 0.02 \mathrm{~d}$ & $1.30 \pm 0.05 \mathrm{~d}$ \\
\hline
\end{tabular}


Table 6 Correlation analysis of microbial PLFA concentrations and soil nutrients in different forest types of the Daiyun Mountains

\begin{tabular}{cccccccc}
\hline Factor & Bacteria & Fungi & Actinomycetes & Protozoa & OM & TN & TP \\
\hline Fungi & $0.97^{* *}$ & 1 & & & & & \\
Actinomycete & $0.89^{*}$ & $0.93^{*}$ & 1 & & & & \\
Protozoa & $0.98^{* *}$ & $0.96^{*}$ & $0.95^{*}$ & 1 & & & \\
OM & $0.94^{*}$ & $0.99^{* *}$ & $0.94^{*}$ & $0.93^{*}$ & 1 & & \\
TN & $0.95^{*}$ & $0.97^{* *}$ & 0.82 & $0.89^{*}$ & $0.96^{*}$ & 1 & \\
TP & $0.91^{*}$ & $0.96^{*}$ & 0.78 & 0.85 & $0.95^{*}$ & $0.99^{* *}$ & 1 \\
TK & $0.98^{* *}$ & $1.00^{* *}$ & $0.94^{*}$ & $0.97^{* *}$ & $0.99^{* *}$ & $0.96^{* *}$ & $0.94^{*}$ \\
\hline
\end{tabular}

456 461

\begin{tabular}{ccccccccc}
\multicolumn{7}{c}{ different forest types of the Daiyun Mountains } \\
\hline Factor & Bacteria & Fungus & Actinomycetes & Protozoa & PMEase & Inv & PPO & Ure \\
\hline Fungi & $0.97^{* *}$ & 1 & & & & & & \\
Actinomycete & $0.89^{*}$ & $0.93^{*}$ & 1 & & & & & \\
Protozoa & $0.98^{* *}$ & $0.96^{*}$ & $0.95^{*}$ & 1 & & & & \\
PMEase & $0.95^{*}$ & $0.99^{* *}$ & $0.97^{* *}$ & $0.97^{* *}$ & 1 & & & \\
Inv & 0.88 & $0.97^{* *}$ & 0.87 & 0.86 & $0.95^{*}$ & 1 & & \\
PPO & $0.98^{* *}$ & $0.93^{*}$ & $0.92^{*}$ & $0.99^{* *}$ & $0.94^{*}$ & 0.8 & 1 & \\
Ure & $0.92^{*}$ & $0.89^{*}$ & $0.97^{* *}$ & $0.98^{* *}$ & $0.93^{*}$ & 0.78 & $0.98^{* *}$ & 1 \\
CAT & $0.99^{* *}$ & $0.96^{*}$ & $0.93^{*}$ & $1.00^{* *}$ & $0.96^{* *}$ & 0.85 & $1.00^{* *}$ & $0.96^{* *}$ \\
\hline
\end{tabular}

Note; ${ }^{*}$ means $P<0.05$, significant correlation; ${ }^{* *}$ means $P<0.01$, extremely significant correlation.

Table 7 Correlation analysis of microbial PLFA concentrations and soil enzyme activity in different forest types of the Daiyun Mountains
462

Table 8 Correlation analysis of soil contents and microbial diversity in different forest types of the Daiyun Mountains

\begin{tabular}{ccccccccccc}
\hline Factor & PH & TN & TP & TK & OM & PMEase & Inv & PPO & Ure & CAT \\
\hline Simpson index & -0.38 & 0.59 & 0.51 & 0.77 & 0.7 & 0.79 & 0.56 & $0.91^{*}$ & $0.96^{*}$ & 0.87 \\
Shannon index & -0.8 & $0.93^{*}$ & $0.89 *$ & $0.97 * *$ & $0.92^{*}$ & $0.94^{*}$ & 0.85 & $0.99 * *$ & $0.93 *$ & $0.99 * *$ \\
Brillouin index & -0.83 & $0.94^{*}$ & $0.91^{*}$ & $0.99^{* *}$ & $0.96^{* *}$ & $0.98^{* *}$ & $0.90^{*}$ & $0.98^{* *}$ & $0.95^{*}$ & $0.99^{* *}$ \\
McIntosh index & $0.99^{* *}$ & $-0.97^{* *}$ & $-0.99^{* *}$ & $-0.91^{*}$ & $-0.94^{*}$ & $-0.89^{*}$ & $-0.98^{* *}$ & -0.74 & -0.67 & -0.8 \\
\hline
\end{tabular}






474 Fig 1 PCA of different soil microbial groups' PLFA in different forest types of the Daiyun Mountains 